\title{
FORMULATION, SYSTEMATIC OPTIMIZATION, IN VITRO, EX VIVO, AND STABILITY ASSESSMENT OF TRANSETHOSOME BASED GEL OF CURCUMIN
}

\section{PRABHJOT KAUR, VARUN GARG, PALAK BAWA, ROOPESH SHARMA, SACHIN KUMAR SINGH*, BIMLESH KUMAR, MONICA GULATI, NARENDRA KUMAR PANDEY, RAKESH NARANG, SHEETU WADHWA, SOUVIK MOHANTA, JIVAN JYOTI, SANANDA SOM}

Department of Pharmacy, School of Pharmaceutical Sciences, Lovely Professional University, Phagwara - 144 411, Punjab, India. Email: Singhsachin23@gmail.com

Received: 12 February 2018, Revised and Accepted: 16 March 2018

ABSTRACT

Objectives: The current work presents a formulation of curcumin-loaded transethosome (CRM-TE) in the form of a gel and its characterization.

Methods: Thirteen formulations were prepared by varying the concentration of Phospholipon 90G as lipid, ethanol, and ratio of lipid: Span using BoxBehnken Design. The optimized formulation was characterized by vesicle size, entrapment efficiency, drug retention, drug permeation through skin, and morphology. Parameters of CRM-TE were compared to other vesicular systems that include liposomes, ethosomes, and transfersomes. Optimized CRM-TE was incorporated into gels, and comparative evaluation was performed. CRM-TE gel was kept at $5 \pm 3^{\circ} \mathrm{C}, 25 \pm 3^{\circ} \mathrm{C}$, and $40 \pm 3^{\circ} \mathrm{C}$ for 180 days, further evaluated for entrapment efficacy and vesicle size.

Results: CRM-TE showed $286.4 \mathrm{~nm}$ vesicle size, $61.2 \%$ entrapment efficiency, $19.8 \%$ drug retention, and $71.3 \%$ drug permeation at $24 \mathrm{~h}$ in the skin. It was found superior in terms of all the parameters as compared to other vesicular formulations. CRM-TE gel also exhibited best characteristics in terms of entrapment efficiency, drug retention, and drug permeation. CRM-TE gel exhibited better stability at $5 \pm 3^{\circ} \mathrm{C}$ in terms of vesicle size and entrapment efficiency as compared to other storage conditions.

Conclusion: CRM-TE gel could offer efficient delivery of curcumin through topical route.

Keywords: Curcumin, Transethosome, Curcumin-loaded transethosome gel, Box-Behnken Design, Stability studies.

(C) 2018 The Authors. Published by Innovare Academic Sciences Pvt Ltd. This is an open access article under the CC BY license (http://creativecommons. org/licenses/by/4. 0/) DOI: http://dx.doi.org/10.22159/ajpcr.2018.v11s2.28563

\section{INTRODUCTION}

Curcumin is obtained from rhizomes of Curcuma longa that belongs to Zingiberaceae family [1]. It is one of the most widely used drugs for the treatment of arthritis, cancer, various inflammatory, neurodegenerative, dermal, metabolic disorders, and viral diseases [2]. It exhibits its anti-inflammatory effect by the inhibition of cyclooxygenase-II and lipoxygenase, suppressing the activation of nuclear factor- $\kappa$ B. Being such a promising therapy in the treatment of many disorders, its use is limited due to its low aqueous solubility $(0.0004 \mathrm{mg} / \mathrm{ml}$ at $\mathrm{pH} 7.3)$ leading to its low oral bioavailability.

Only the traces of curcumin observed after oral administration due to its poor absorption (up to $8 \mathrm{~g} /$ day) [3]. Since the patients suffering from diseases where long-term therapy is required (e.g. arthritis) have to take the drug on daily basis throughout their lives, drug may get deposited in the tissues, leading to further complications. Hence, in the present work, an attempt was made to develop a topical drug delivery system to increase the bioavailability of the drug. Bypassing of the first pass metabolism and local action could be achieved by the proposed delivery system. Very small dose of orally administered formulations about $25-45 \%$ reaches the blood circulation due to the first pass effect. To overcome these limitations, the concept of gel formulations comes into existence for topical applications [4].

Despite these expected advantages, conventional topical systems reported hitherto, show many limitations in terms of deeper penetration of the skin. This problem can be overcome by the use of vesicular drug delivery systems such as liposomes (L), niosomes, transfersomes (T), and ethosomes (E) [5]. The problem of the low flexibility of L could be overcome by the use of $\mathrm{E}$ and $\mathrm{T}$. T are composed of lipids and edge activators while E are composed of lipid and ethanol, leading to high permeation of drug [6]. Transethosomes (TE) are a new generation of vesicles which interplay the role of $\mathrm{E}$ as well as $\mathrm{T}$ [5]. These contain lipid, ethanol as well as edge activator such as span 80, span 60, and tween 80 and therefore, synergize the properties of both E and T [6].

In the present study, formulation of TE has been attempted, and the developed carrier system has been successfully applied to formulate gel for the topical delivery of curcumin. Optimization of formulation variables that could affect the formulation properties of TE has also been carried out using Box-Behnken design (BBD).

\section{MATERIALS AND METHODS}

\section{Materials}

Curcumin was procured from Sanjay Biologicals Pvt. Ltd., Amritsar, Punjab, India. Phospholipon 90 and 70 G (PL 90 G and 70 G), egg lecithin was gifted by Lipoid, Germany. Sephadex G-50 (medium) was purchased from M/s Sigma-Aldrich, St. Louis, USA. Span 20, 60, 80 , tween 20,40,80, and ethanol were procured from Loba Chemie Pvt. Ltd, Mumbai, India. All the other chemicals used for formulation development were of analytical grade. Double distilled water was used throughout the study.

High-performance liquid chromatography (HPLC) method for curcumin

Estimation of curcumin was carried out using reverse phase HPLC (LC-20 AD; Shimadzu, Japan). The stationary phase used was C-18 reverse phase column (Nucleodur C18). The length of the column was $250 \mathrm{~mm}$, width $4.6 \mathrm{~mm}$ and internal diameter was $5 \mu \mathrm{m}$. The mixture of $60 \% \mathrm{v} / \mathrm{v}$ acetonitrile and $40 \% \mathrm{v} / \mathrm{v}$ acetate buffer (5\%) was used as 
a mobile phase at a flow rate of $1 \mathrm{~mL} / \mathrm{min}$. Photodiode array detector (SPDM20A; Shimadzu, Japan) with a $20 \mu \mathrm{L}$ loop (Rheodyne) was used to quantify the drug at $420 \mathrm{~nm}$. LC Solution software was used as data station. The prepared calibration curve found linear in the range of $2-10 \mu \mathrm{g} / \mathrm{mL}$ with $\mathrm{r}^{2}$ value of 0.9939 and retention time of $6.9 \mathrm{~min}$.

\section{Preliminary screening studies}

Preliminary screening studies were carried out to identify suitable levels for the formulation variables influencing physicochemical properties of vesicles. Different lipids, for example, Oya phospholipid (PL 90 G, PL 70 G), egg phospholipid (egg lecithin), and edge activators (Span 20, 60, and 80, tween 20, 40, and 80) were used. During the preliminary studies, results revealed that among lipids used, PL $90 \mathrm{G}$ and among the edge activators, span 80 showed the best results. Hence, these two were selected as independent variables. Using various ratios of these two along with ethanol, further formulations were designed. A total of 20 formulations were prepared using 10-40\% ethanol and $1-5 \%$ lipid and lipid and span 80 in the ratio of 85:15 (Table 1). The prepared formulations were evaluated for entrapment efficiency, percentage transmittance, and optical microscopy as the responses in preliminary screening studies.

\section{Formulation of TE and other vesicles}

For the preparation of vesicles, three different methods (a) ethanol injection method, (b) thin film hydration method, and (c) rapid ethanol injection method were used. Among them, ethanol injection method was found to give best results. 20 different formulations were prepared using formula compositions that are mentioned in Table 1. Combination of PL 90 G (phospholipid) and Span 80 (edge activator) was used for the formulation of vesicles. Lipid, edge activator, and drug (curcumin) were weighed accurately and dissolved in ethanol. Phosphate buffer ( $\mathrm{pH} 7.4)$ was maintained at a temperature of $50^{\circ} \mathrm{C}$ in another vessel. Ethanolic solution of PL 90 G, Span 80, and drug was injected into aqueous solution dropwise at the rate of $1 \mathrm{ml} / \mathrm{min}$ with constant stirring [6].

\section{Design of experiment}

Initial screening trials were conducted to evaluate the formulation parameters that may influence the properties of vesicles. Factors such as percentage of edge activator, lipid, and ethanol were taken as critical parameters of the formulation. Based on the number of factors and their levels, BBD was applied to evaluate the effect of formulation and processing parameters affecting physical properties of TE. Percentage of SPL 90, ethanol, and SPL 90: Span 80 ratio was taken as critical parameters that may influence the entrapment efficacy, vesicle size, and skin permeation of the vesicles. These three parameters were operated at three levels $(+1,0$, and -1$)$. The concentration of the drug, type of phospholipid and type of edge activator were kept same for all the experiments. Design-Expert 9.0.3 software (Stat-Ease, USA) was used to conduct the study. A total of 13 formulations were designed by the software with 2 centric points. Experiments were run in random order to increase the predictability of model. The independent factors and their design level used in the study is shown in Table 2.

\section{Characterization of prepared formulation}

Drug entrapment efficiency

Entrapment efficiency of the prepared formulations was studied by mini column centrifugation method according to the method reported by Garg et al. (2016), using the following equation [6].

Percentage entrapment efficiency $=\frac{\text { Amount of entrapped drug }}{\text { Total amount of drug }} \times 100$

\section{Vesicle size analysis}

Vesicle size and size distribution study was done using Beckman Coulter (Delsa nano ${ }^{\circledR}$ ) using dynamic light spectroscopy. Study was conducted in triplicate and mean data were recorded.

\section{Ex vivo skin permeation study}

Fresh abdominal skin of goat was used for skin permeation studies. Skin was obtained from local slaughterhouse. The tissue was then washed with distilled water to remove the mucous and other adhered matrices. Tissues of about $0.2 \mathrm{~mm}$ thickness and $3 \mathrm{~cm}$ length were mounted on Franz diffusion cell having surface area of $1.79 \mathrm{~cm}^{2}$ and volume of $25 \mathrm{~mL}$. The tissue was stabilized using mixture of methanol and $0.2 \mathrm{M}$ phosphate buffer saline ( $\mathrm{pH} 7.4$ ) in the ratio of 1:9 as medium, in both, donor and receptor compartments with magnetic stirring for $30 \mathrm{~min}$. At the end of $30 \mathrm{~min}$, the existing buffers in both the compartments were replaced with fresh medium. The receptor compartment was stirred at $100 \mathrm{rpm}$. Formulation (1 ml) was kept in donor compartment over the goat skin which acted as diffusion barrier. Study was conducted for 24 h. Samples were withdrawn at fixed intervals and replaced with same amount of fresh media to maintain sink conditions. Sample analysis was carried out using HPLC. Each study was carried out in triplicate

Table 1: Pre-screening studies

\begin{tabular}{|c|c|c|c|c|c|c|c|c|}
\hline $\begin{array}{l}\text { Formulation } \\
\text { code }\end{array}$ & $\begin{array}{l}\text { Lipid: } \\
\text { Span } 80\end{array}$ & $\begin{array}{l}\text { Lipid }(\%) \\
\text { (mg for } 10 \mathrm{ml} \text { ) }\end{array}$ & $\begin{array}{l}\text { Span } 80 \\
(\mathrm{mg} \text { for } 10 \mathrm{ml})\end{array}$ & $\begin{array}{l}\text { Ethanol } \\
\text { (\%) }\end{array}$ & $\begin{array}{l}\text { Phosphate } \\
\text { buffer }(\mathrm{ml})\end{array}$ & $\begin{array}{l}\text { Agglomeration } \\
\text { rate* }\end{array}$ & $\begin{array}{l}\% \text { Entrapment } \\
\text { efficiency } \\
(\text { Mean } \pm S D)(n=3)^{* *}\end{array}$ & $\begin{array}{l}\% \text { Transmittance } \\
(M e a n \pm S D) \\
(n=3)^{* *}\end{array}$ \\
\hline F1 & $85: 15$ & $1(100 \mathrm{mg})$ & 17.6 & 10 & 9 & 1 & $66.90 \pm 0.01$ & $78.9 \pm 0.01$ \\
\hline F2 & $85: 15$ & $1(100 \mathrm{mg})$ & 17.6 & 20 & 8 & 1 & $24.40 \pm 0.01$ & $83.6 \pm 0.01$ \\
\hline F3 & $85: 15$ & $1(100 \mathrm{mg})$ & 17.6 & 30 & 7 & 2 & $45.10 \pm 0.01$ & $83.5 \pm 0.01$ \\
\hline $\mathrm{F} 4$ & $85: 15$ & $1(100 \mathrm{mg})$ & 17.6 & 40 & 6 & 2 & $57.40 \pm 0.01$ & $63.8 \pm 0.01$ \\
\hline F5 & $85: 15$ & $2(200 \mathrm{mg})$ & 35.2 & 10 & 9 & 3 & $59.90 \pm 0.01$ & $82.4 \pm 0.02$ \\
\hline F7 & $85: 15$ & $2(200 \mathrm{mg})$ & 35.2 & 30 & 7 & 1 & $83.30 \pm 0.01$ & $64.1 \pm 0.01$ \\
\hline F8 & $85: 15$ & $2(200 \mathrm{mg})$ & 35.2 & 40 & 6 & 2 & $88.60 \pm 0.02$ & $71.7 \pm 0.02$ \\
\hline F9 & $85: 15$ & $3(300 \mathrm{mg})$ & 52.9 & 10 & 9 & 2 & $31.10 \pm 0.02$ & $13.7 \pm 0.01$ \\
\hline F10 & $85: 15$ & $3(300 \mathrm{mg})$ & 52.9 & 20 & 8 & 2 & $51.90 \pm 0.01$ & $78.0 \pm 0.01$ \\
\hline F11 & $85: 15$ & 3 (300 mg) & 52.9 & 30 & 7 & 2 & $73.60 \pm 0.01$ & $26.3 \pm 0.01$ \\
\hline F12 & $85: 15$ & $3(300 \mathrm{mg})$ & 52.9 & 40 & 6 & 3 & $24.40 \pm 0.01$ & $56.8 \pm 0.02$ \\
\hline F13 & $85: 15$ & 4 (400mg) & 70.55 & 10 & 9 & 3 & $28.71 \pm 0.01$ & $39.0 \pm 0.01$ \\
\hline F14 & $85: 15$ & $4(400 \mathrm{mg})$ & 70.55 & 20 & 8 & 2 & $21.13 \pm 0.01$ & $42.0 \pm 0.01$ \\
\hline F16 & $85: 15$ & $4(400 \mathrm{mg})$ & 70.55 & 40 & 6 & 1 & $55.22 \pm 0.01$ & $31.4 \pm 0.01$ \\
\hline F17 & $85: 15$ & $5(500 \mathrm{mg})$ & 88.2 & 10 & 9 & 2 & $15.81 \pm 0.01$ & $23.1 \pm 0.01$ \\
\hline F18 & $85: 15$ & $5(500 \mathrm{mg})$ & 88.2 & 20 & 8 & 2 & $39.60 \pm 0.01$ & $21.7 \pm 0.02$ \\
\hline F19 & $85: 15$ & $5(500 \mathrm{mg})$ & 88.2 & 30 & 7 & 1 & $87.00 \pm 0.01$ & $13.9 \pm 0.03$ \\
\hline F20 & $85: 15$ & $5(500 \mathrm{mg})$ & 88.2 & 40 & 6 & 1 & $64.50 \pm 0.02$ & $31.0 \pm 0.004$ \\
\hline
\end{tabular}

SD: Standard deviation 
and mean was recorded. The permeation profile was constructed by plotting percentage of drug permeated versus time (h).

\section{Skin retention study}

Skin was washed with $0.2 \mathrm{M}$ phosphate buffered saline $(7.4 \mathrm{pH})$ 3-4 times to remove the adhered formulation. To confirm the complete removal of any adhering drug, the washings were subjected to HPLC. The absence of drug peak indicated that the skin was free from any adhered drug. Cleaned skin was cut into small pieces and kept in mixture of methanol and $0.2 \mathrm{M}$ phosphate buffer saline (pH 7.4) in the ratio of 1:9 for $24 \mathrm{~h}$ to extract out the drug deposited inside the skin. After $24 \mathrm{~h}$, the medium was sonicated and centrifuged. Supernatant was collected and analyzed using HPLC for quantitation of drug. Each study was condcuted in triplicate and mean data were recorded.

\section{Morphological study of optimized batch of TE (OTE)}

The optimized formulation was evaluated for its morphology by transmission electron microscopy (TEM). A drop of the diluted sample was placed on a microscopic copper-coated grid for drying. After complete drying, a drop of a $1 \%$ phosphotungstic acid aqueous solution was added for negative staining. Excess solution was wiped off after 45 $\mathrm{s}$ and sample was analyzed under microscope at different magnification values [7].

\section{Stability study of OTE}

Optimized formulation was kept at $5 \pm 3^{\circ} \mathrm{C}, 25 \pm 3^{\circ} \mathrm{C}$, and $40 \pm 3^{\circ} \mathrm{C}$ for 180 days, further evaluated for entrapment efficacy and vesicle size.

\section{Preparation of other vesicles}

To compare the potential of developed TE in terms of physical properties, other vesicles such as L, transfersome (T), and ethosome (E) were also prepared. The composition of these vesicles is presented in Table 3. Ethosomes were prepared by the same method as that TE, whereas $\mathrm{L}$ and transfersome were prepared by thin film hydration method. PL 90 G, Span 80, and drug were weighed accurately and dissolved in chloroform/methanol $(2: 1 \mathrm{v} / \mathrm{v})$. This solution was evaporated on a rotary evaporator at $50^{\circ} \mathrm{C}$ under reduced pressure. The thin film obtained was hydrated with $\mathrm{pH} 7.4$ phosphate buffer. The suspension was kept overnight for complete hydration of the vesicles [6].

\section{Preparation of vesicular gel formulation}

All the prepared vesicles were incorporated into Carbopol $934^{\circledR}$ gel $1 \% \mathrm{w} / \mathrm{w}$. These were termed as optimized TE based gel (OTEG), transfersome based gel (TG), ethosome based gel (EG), and liposomebased gel (LG), respectively. Gel was prepared by incorporating vesicular dispersion equivalent to $0.5 \% \mathrm{w} / \mathrm{w}$ of drug to $10 \% \mathrm{w} / \mathrm{w}$ of Carbopol $934^{\circledast}$ gel. The final composition of the gel thus was $1 \% \mathrm{w} / \mathrm{w}$ of Carbopol gel. Triethanolamine was added to the gel to impart the desired consistency and $\mathrm{pH}$ (5.1).

\section{Characterization of prepared gel}

Appearance and $\mathrm{pH}$

The prepared gel was evaluated visually for $\mathrm{pH}$, clarity, color and presence of any particles. Two grams of gel were stirred in distilled water and volume was made up to $50 \mathrm{~mL}$. $\mathrm{pH}$ was measured using digital $\mathrm{pH}$ meter.

\section{Measurement of viscosity}

Viscosity of the prepared formulation was determined using Brookfield viscometer at different shear rates and torque values. Spindle No. 64 was used to measure the viscosity. Measurement was done over the range of $2-100 / s$.

\section{Ex vivo skin permeation study of gel formulations}

Drug release from TE based gel was compared with transfersome, ethosome, and liposome-based gel using results of skin permeation study that was carried out for $24 \mathrm{~h}$. Drug permeation study of gel was performed in a similar way as described previously for vesicles. Gel (1 g) was used in donor compartment. Various release mechanisms such as zero-order, first-order, Higuchi, and Hixson-Crowell were fitted to optimized and other gel formulations to find out the release mechanism.

\section{Skin retention study of gel formulations}

Skin retention of OTEG was compared with transfersome, ethosome, and liposome-based gel. The study was conducted in similar manner as described for vesicle-based formulation. Each study was carried out in triplicate and mean data were recorded.

Table 2: Box-Behnken Design deciphering design levels of independent variables and their responses

\begin{tabular}{|c|c|c|c|c|c|c|}
\hline $\begin{array}{l}\text { Formulation } \\
\text { code }\end{array}$ & Lipid (\%) (A) & $\begin{array}{l}\text { Lipid: Span } \\
80 \text { (B) }\end{array}$ & Ethanol (\%) (C) & $\begin{array}{l}\text { Vesicle size }(\mathrm{nm}) \\
(M e a n \pm S D) \\
(\mathrm{n}=3)^{*}\left(\mathrm{Y}_{1}\right)\end{array}$ & $\begin{array}{l}\text { Entrapment efficiency }(\%) \\
(\text { Mean } \pm \text { SD) } \\
(\mathrm{n}=3)^{*}\left(\mathrm{Y}_{2}\right)\end{array}$ & $\begin{array}{l}\text { Skin permeation } \\
(\text { Mean } \pm S D)(\%) \\
(n=3) *\left(Y_{3}\right)\end{array}$ \\
\hline A1 & $4(+1)$ & 11.5 & $30(+1)$ & $740.00 \pm 0.01$ & $52.31 \pm 0.01$ & $73.70 \pm 0.01$ \\
\hline $\mathrm{A} 2$ & $1(-1)$ & $4(-1)$ & $20(0)$ & $710.00 \pm 0.01$ & $41.01 \pm 0.01$ & $27.20 \pm 0.01$ \\
\hline A3 & $2.5(0)$ & $19(+1)$ & $10(-1)$ & $493.70 \pm 0.02$ & $49.67 \pm 0.01$ & $37.70 \pm 0.02$ \\
\hline $\mathrm{A} 4$ & $2.5(0)$ & $19(+1)$ & $30(+1)$ & $442.30 \pm 0.01$ & $64.30 \pm 0.02$ & $52.90 \pm 0.01$ \\
\hline A5 & $4(+1)$ & $11.5(0)$ & $10(-1)$ & $470.80 \pm 0.02$ & $41.70 \pm 0.02$ & $70.80 \pm 0.02$ \\
\hline A7 & $1(-1)$ & $11.5(0)$ & $10(-1)$ & $967.30 \pm 0.02$ & $43.00 \pm 0.02$ & $49.90 \pm 0.02$ \\
\hline A8 & $2.5(0)$ & $4(-1)$ & $30(+1)$ & $1175.00 \pm 0.03$ & $75.80 \pm 0.02$ & $80.20 \pm 0.02$ \\
\hline A9 & $1(-1)$ & $11.5(0)$ & $30(+1)$ & $303.60 \pm 0.01$ & $49.96 \pm 0.01$ & $66.70 \pm 0.02$ \\
\hline A10 & $2.5(0)$ & $4(-1)$ & $10(-1)$ & $654.40 \pm 0.01$ & $57.87 \pm 0.01$ & $44.70 \pm 0.02$ \\
\hline A11 & $1(-1)$ & $19(+1)$ & $20(0)$ & $874.40 \pm 0.02$ & $57.42 \pm 0.01$ & $11.80 \pm 0.01$ \\
\hline A12 & $4(+1)$ & $19(+1)$ & $20(0)$ & $413.00 \pm 0.01$ & $49.70 \pm 0.02$ & $82.30 \pm 0.02$ \\
\hline A13 & $4(+1)$ & $4(-1)$ & $20(0)$ & $844.50 \pm 0.02$ & $46.33 \pm 0.02$ & $84.00 \pm 0.01$ \\
\hline
\end{tabular}

${ }^{*}$ n: No of replicates of study conducted. SD: Standard deviation

Table 3: Composition of vesicles

\begin{tabular}{lllll}
\hline Formulation code & Phospholipon $\mathbf{9 0}$ G $(\% \mathbf{w} / \mathbf{v})$ & Lipid: Span $\mathbf{8 0}$ & Ethanol (\%) & Chloroform: Methanol \\
\hline OTE & 3.49 & 19.00 & 30 & - \\
T & 3.49 & 19.00 & - & $2: 1$ \\
E & 3.49 & 19.00 & 30 & - \\
L & 1.49 & 19.00 & - & $2: 1$ \\
\hline
\end{tabular}

OTE: Optimized batch of transethosomes, T: Transfersome, E: Ethosome, L: Liposomes 
Statistical analysis

All the results are expressed as mean \pm standard deviation. Analysis of variance (ANOVA) was used as statistical tool to find possible correlations using GraphPad Prism version 7 (GraphPad Software Inc., CA, USA). The results were found significant where $\mathrm{p}<0.05$. All the studies related to design and optimization of formulation was carried out using Design-Expert 9.0.3 software.

\section{RESULTS AND DISCUSSION}

\section{Response surface analysis using BBD and optimization of formulation}

For the preparation of vesicles, three different methods (a) ethanol injection method, (b) thin film hydration method, and (c) rapid ethanol injection method were used. The amount of lipid and ethanol was kept constant at $3 \% \mathrm{w} / \mathrm{v}$ and $30 \% \mathrm{v} / \mathrm{v}$, respectively. The ratio of lipid to span 80 was varied in the range of 75:25-95:5. The study revealed different types of responses for different methods used. In case of ethanol injection method (P11), the results of optical microscopy revealed the presence of high amount of debris along with high agglomeration rate. This method was, therefore, not used for further studies. Film hydration method (P6-10) produced spherical and multilamellar vesicles. These were not considered optimum due to the desirability of unilamellar vesicles (ULVs) because of the requirement of transdermal delivery [8]. Moreover, drug leaching has been reported to be high in case of multilamellar vesicles (MLVs) [9]. Formation of ULVs was observed when vesicles were prepared using ethanol injection method (P1-5). Hence, ethanol injection method was used for further preparations.

It is important to note that on variation in the ratio of lipid (Phospholipon 90) to span 80, no significant differences in terms of vesicle morphology and percent transmittance were observed in any case except formulation P3. In case of P3, there was the absence of agglomeration and percentage transmittance was comparatively higher. High percentage transmittance value is an indication that vesicle size would be comparatively smaller [10].

Hence, to select critical formulation variables along with their ratios, 20 different formulations (F1-F20) were further explored by varying lipid $(1-5 \% \mathrm{w} / \mathrm{v})$ and ethanol concentration $(10-40 \% \mathrm{v} / \mathrm{v})$. It can be noted that lipid to span 80 ratios was kept 85:15 since it has provided good results. The results of responses are shown in Table 1. It was observed from optical microscopy that in formulations F1, 2, 6, 7, 16, 19 , and 20, agglomeration rate was very less and spherical ULVs were formed (results not shown). However, in formulation F5, 12, and 13 agglomeration rates were found to be very high. In formulations F5, $6,13,15,16$, and 17 , vesicles were spherical in shape but with a high amount of debris. Entrapment efficiency for formulations was found in a range of 12.3-88.6\%. It was observed that F8 formulation showed maximum entrapment efficiency, i.e., $88.6 \%$. From transmittance data, it was observed that F2 formulation showed the highest value, i.e., 83.6\%. Significant changes were observed in entrapment efficiency as well as percentage transmittance when lipid concentration was varied from 1 to $5 \%$ and ethanol concentration from 10 to $40 \%$. Thus, considering these responses, lipid concentration was varied between 1 and $4 \%$, ethanol concentration between $10 \%$ and $30 \%$ and the ratio of lipid to span 80 was varied in between 4 and 20 for further experimental design to optimize the formulation.

A total of 13 experiments using BBD were designed to study the effect of ethanol, PL 90, and Span 80 on vesicle size (y1), entrapment efficiency $(y 2)$, and skin permeation of drug at $24 \mathrm{~h}\left(\mathrm{Q}_{24}\right)(y 3)$. The responses are illustrated in Table 2 .

The data revealed responses $y 1, y 2$, and $y 3$ in the range of 303.6 to $1175 \mathrm{~nm}, 41.01$ to $75.8 \%$, and 11.86 to $84.01 \%$, respectively. The significance of model was confirmed through the data obtained by carrying out ANOVA as the model Prob was greater than $\mathrm{F}$ and $\mathrm{p}<0.05$. $\mathrm{p}$ value for vesicle size $(y 1)$, entrapment efficiency $(y 2)$, and skin permeation of drug after $24 \mathrm{~h}(y 3)$ were found to be $0.0108,0.0004$,
0.0200 and 0.0014 , respectively. The model $\mathrm{F}$ values for response $y 1$, $y 2$, and $y 3$ were $20.26,38.26,61.22$, and 48.96 , respectively, which implied that model was significant. The multiple regression terms $\left(\mathrm{R}^{2}\right)$ were also analyzed. The predicted $\mathrm{R}^{2}$ values for response $y 1, y 2, y 3$, and $y 4$ were found to be $0.9906,0.8310,0.8188$, and 0.9691 , respectively. Adjusted $\mathrm{R}^{2}$ values for response $y 1, y 2, y 3$, and $y 4$ were found to be $0.9918,0.9622,0.9693$, and 0.9752 , respectively. The predicted $R^{2}$ value was found to be in closer agreement with adjusted $R^{2}$ value as the difference between adjusted $R^{2}$ and predicted $R^{2}$ values is $<2$. This indicated that the model has predicted the responses very well [11]. It is important to note that adequate precision measures the signal to noise ratio and a ratio $>4$ is desirable [12]. For responses $y 1, y 3, y 3$, and $y 4$, the ratio was $88.857,24.267,27.211$, and 40.912 , respectively. Hence, this model could be used to navigate the design space. The final mathematical model in terms of coded factors as described by the Design Expert software is shown below in Eqs. (2-4) for responses $y 1$, $y 2$, and $y 3$, respectively.

y1 [Vesicle size $(\mathrm{nm})]=+691.82-48.37 \times \mathrm{A}-145.06 \times \mathrm{B}+9.34 \times \mathrm{C}-$ $148.98 \times \mathrm{AB}+233.23 \times \mathrm{AC}-143 \times \mathrm{BC}$

y2 [Entrapment efficiency (\%)] $=+65.50-0.17 \times \mathrm{A}+1.29691 \times \mathrm{B}+6.27 \times \mathrm{C}-$ $3.26 \times \mathrm{AB}+0.91 \times \mathrm{AC}-0.83 \times \mathrm{BC}-16.03 \times \mathrm{A}^{2}-0.86 \times \mathrm{B}^{2}-2.73 \times \mathrm{C}^{2}$

y3 [Skin permeation of drug at $24 \mathrm{~h}(\%)]=+22.30+13.60 \times \mathrm{A}+$ $13.52 \times \mathrm{B}+10.11 \times \mathrm{C}+15.06 \times \mathrm{AB}+3.49 \times \mathrm{AC}+2.43 \times \mathrm{BC}+27.37 \times \mathrm{A}^{2}+13.33 \times$ $\mathrm{B}^{2}+15.63 \times \mathrm{C}^{2}$

In the polynomial equation, a positive sign represents a synergistic effect, while a negative sign indicates an antagonistic effect. In case of $y 1$, the data revealed that with an increase in PL $90 \mathrm{G}$ concentration (A) and ratio of PL 90 G to Span 80 (B), the vesicle size got decreased, whereas, with an increase in ethanol concentration, vesicle size got increased. This reveals that higher PL 90 G concentration and PL 90 $\mathrm{G}$ to span 80 ratios as well as the lower concentration of ethanol are desirable to control vesicle size in the lower range. Moreover, the combined effect of Factors $\mathrm{A}$ and $\mathrm{B}$ and $\mathrm{B}$ and $\mathrm{C}$ revealed a decrease in vesicle size. On the contrary, the combinative effect of A and C causes an increase in the vesicle size. As an outcome, it can be understood that the concentration of all the factors should be neither too high nor very low to get optimum vesicle size.

In case of entrapment efficiency ( $y 2)$, it was observed that $y 2$ got decreased with increased concentration of $\mathrm{A}$, however, at a higher level of B and C, entrapment efficiency ( $y 2$ ) of vesicles got increased. This revealed that increased level of the ratio of PL 90 G to span 80 and ethanol was desirable to increase entrapment efficiency of vesicles. Ethanol fluidizes the lipid layer of vesicles and thereby increases the fluidity as well as the flexibility of vesicles leading to better entrapment efficiency [6]. When the combinative effect of factors on $y 3$ was observed, the response got decreased with increased concentration of Factors $\mathrm{AB}$ and $\mathrm{BC}$. On the other hand, it got increased with increase in factor AC. This revealed that presence of higher concentration of PL $90 \mathrm{G}$ and PL $90 \mathrm{G}$ to span 80 ratios, restricts the penetration of the drug in the lipid bilayer, whereas, the presence of ethanol in higher concentration nullifies this effect.

In case of skin permeation of drug (y3), the response got significantly increased with increase in the concentration of all the three factors. The major reason behind this is permeation enhancing capacity of ethanol that was further enhanced due to the combined effect of phospholipid and span 80 [6].

The obtained regression model helped in generation of 3D response surfaces for independent factors ( $y 1$ to $y 3$ ), by keeping one factor constant in each case. It was observed from 3D plots that for response $y 1$, vesicle size decreased with increase in the concentration of $\mathrm{AB}$ (Fig. 1a) and BC (Fig. 1b), whereas, it increased with increase in concentration of BC (Fig. 1c). The response $y 2$ got decreased with increase in concentration 
of $\mathrm{AB}$ (Fig. 1d) and BC (Fig. 1e). However, it got increased with increase in the level of AC (Fig. 1f). The drug permeation was found to increase with an increase in all the three variables (Fig. 1g-i).

Employment of graphical optimization method helped in choosing the best fit optimum formulation. The data revealed that for an optimum formulation with desirable responses, the amount of PL $90 \mathrm{G}$ and PL 90 G: Span 80 ratio and ethanol percentage should be $3.49 \% \mathrm{w} / \mathrm{v}$, 19 (95:5), and 30\% v/v, respectively.

\section{Validation and characterization of optimized batch}

The optimized batch was prepared using 3.49\% w/v of PL $90 \mathrm{G}$ and 95:5 ratio of PL 90 G: Span 80 and 30\% v/v ethanol and characterized for entrapment efficiency (\%), vesicle size, polydispersity index (PDI), skin permeation, and retention of drug. All the parameters were also compared among E, T, and L-based formulation. Table 4 shows the entrapment efficiency of OTE along with T, E, and L. The data revealed that OTE based formulation was found to give the highest value (61.2\%) followed by $\mathrm{E}$ $(52.0 \%)$. The order of decrease in entrapment efficiency was as follow:

\section{$\mathrm{OTE}>\mathrm{T}>\mathrm{E}>\mathrm{L}$.}

Vesicle size and polydispersity index of various types of formulations were also compared (Table 4). Vesicle size of OTE was found to be least (286.4 nm) as compared to that of the other formulations. PDI of OTE was 0.274 indicating homogeneous population and narrow size distribution [13]. Vesicle size was found to decrease in following order:

\section{$\mathrm{L}>\mathrm{T}>\mathrm{E}>\mathrm{OTE}$}

\section{Skin permeation and retention studies}

Data obtained from skin permeation studies revealed that at $24 \mathrm{~h}$, OTE showed the highest permeation of the drug (71.3\%) whereas, L showed the least permeation (40.3\%). Fig. 2 shows comparative permeation of all the formulations for $24 \mathrm{~h}$. At the end of the $6^{\text {th }} \mathrm{h}$, the permeation of drug was found to increase sharply, and this increase was observed to continue until $24 \mathrm{~h}$. On the similar pattern, increase in drug permeation was also observed in case of $\mathrm{E}, \mathrm{T}$, and $\mathrm{L}$. Rate of permeation decreased in the order - OTE $>\mathrm{T}>\mathrm{E}>\mathrm{L}$.

This may be attributed to the fact that liposomes are typically hollow spheres surrounded by a lipid doubled layer. Once applied on the skin surface, they are retained in the upper layer of the stratum corneum, acting as a drug reservoir, whereas, $\mathrm{T}$ and $\mathrm{E}$ can easily change their shape and cross the skin barrier. However, the major limitation of these vesicles is their difficulty to load hydrophobic drugs into the bilayer without compromising their deformability and elastic properties. TE has shown an irregular spherical shape and higher values skin permeation compared to other vesicles. Skin retention potential of vesicles was also calculated (Fig. 3) and was found highest in case of OTE, i.e. 19.8\% followed by T, E, and L, i.e. $13.8 \%, 9.0 \%$, and $7.0 \%$, respectively.

\section{TEM OTE}

TEM image of OTE is shown in Fig. 4. The results obtained from drugloaded OTE revealed the formation of ULVs having spherical but

Table 4: Mean ( \pm SD) entrapment efficiency, particle size, and PDI of OTE, and other vesicles

\begin{tabular}{llll}
\hline $\begin{array}{l}\text { Formulation } \\
\text { code }\end{array}$ & Mean \pm SD $\mathbf{n}=\mathbf{3}$ & $\begin{array}{l}\text { Vesicle } \\
\text { size }(\mathbf{n m})\end{array}$ & PDI \\
\cline { 2 - 3 } & $\begin{array}{l}\text { \% Entrapment } \\
\text { efficiency }\end{array}$ & & \\
\hline OTE & $61.20 \pm 0.01$ & $286.40 \pm 0.02$ & $0.27 \pm 0.01$ \\
T & $54.50 \pm 0.02$ & $521.20 \pm 0.02$ & $0.34 \pm 0.01$ \\
E & $52.00 \pm 0.01$ & $391.90 \pm 0.01$ & $0.27 \pm 0.01$ \\
L & $43.70 \pm 0.02$ & $5737.0 \pm 0.02$ & $1.67 \pm 0.02$ \\
\hline
\end{tabular}

n: No of samples, SD: Standard deviation, OTE: Optimized batch of transethosomes, PDI: Polydispersity index
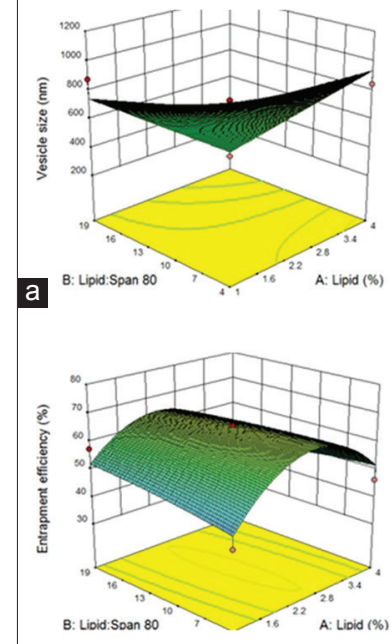

d

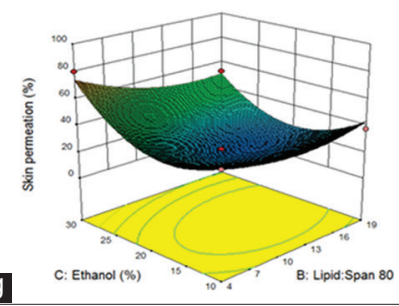

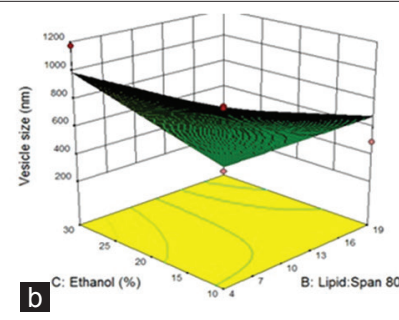

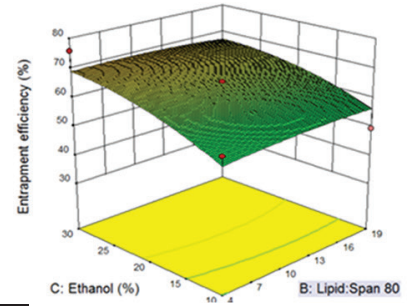

e

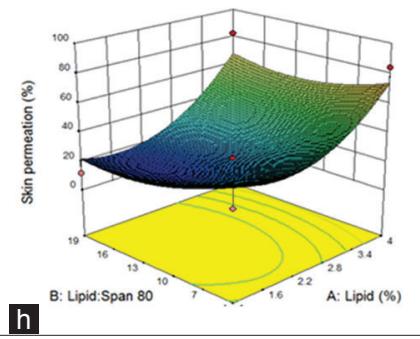

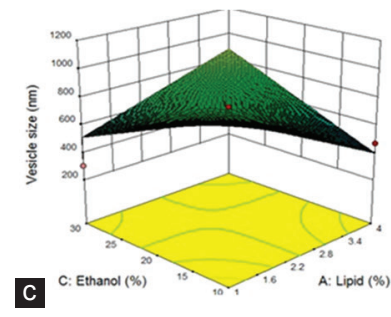

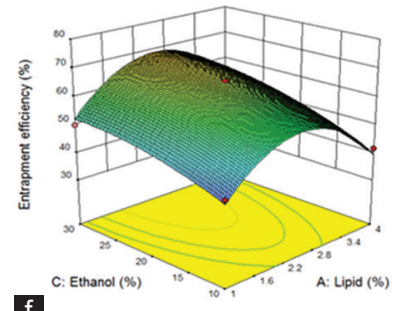

$f$

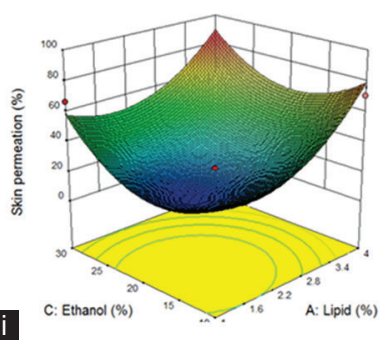

Fig. 1: 3D plots for effect of lipid (phospholipon $90 \mathrm{G}$ ), ethanol, lipid to Span 80 ratio on vesicle size (a-c), percentage entrapment efficiency (d-f), and percentage skin permeation (g-i) 


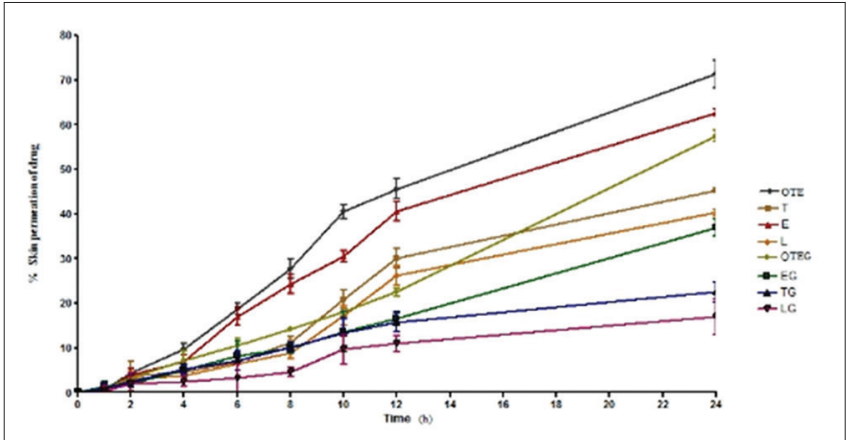

Fig. 2: Mean ( \pm standard deviation) comparative percentage skin permeation of curcumin from vesicles and their gel formulation

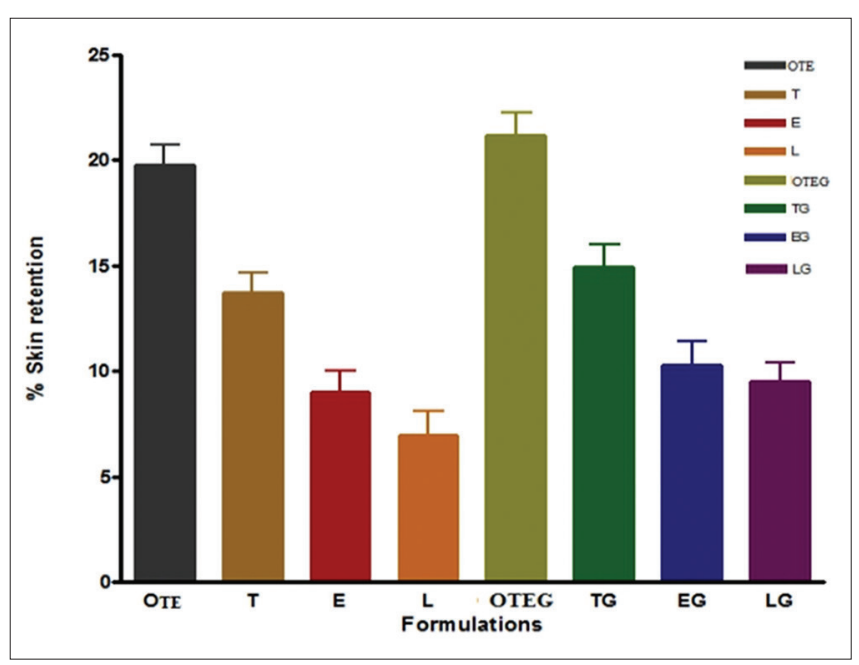

Fig. 3: Mean ( \pm standard deviation) percentage skin retention potential of vesicles and their gel formulation

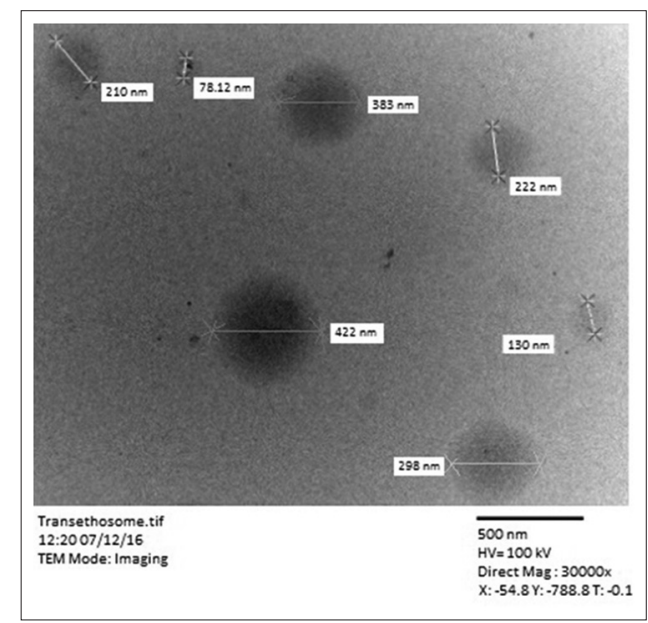

Fig. 4: Transmission electron microscopy image of optimized formulation of optimized batch of transethosomes

irregular shape. The smallest vesicle size observed was $78.12 \mathrm{~nm}$ at $\times 30000$ while in most of the cases, size of vesicles was observed to be near $250 \mathrm{~nm}$. It is reported that ULVs have higher potential to permeate skin as compared to MLVs.

\section{Stability studies}

Table 5 shows the stability data of OTE at $5 \pm 3^{\circ} \mathrm{C}, 25 \pm 3^{\circ} \mathrm{C}$, and $40 \pm 3^{\circ} \mathrm{C}$ for 180 days. The data showed that there was a negligible loss of entrapped drug at $5 \pm 3^{\circ} \mathrm{C}$ after 180 days of storage. However, at $25 \pm 2^{\circ} \mathrm{C}$,
Table 5: Entrapment efficiency, vesicles size, and PDI of OTE at different temperatures after 180 days under different stability conditions

\begin{tabular}{llll}
\hline \multirow{2}{*}{ Temperature } & Mean \pm SD n=3 & & \\
\cline { 2 - 4 } & $\begin{array}{l}\text { Entrapment } \\
\text { efficiency (\%) }\end{array}$ & $\begin{array}{l}\text { Vesicle } \\
\text { size (nm) }\end{array}$ & PDI \\
\hline $5 \pm 3^{\circ} \mathrm{C}$ & $59.20 \pm 0.01$ & $358.30 \pm 0.01$ & $00.29 \pm 0.02$ \\
$25 \pm 3^{\circ} \mathrm{C}$ & $52.60 \pm 0.01$ & $421.40 \pm 0.01$ & $00.32 \pm 0.01$ \\
$40 \pm 3^{\circ} \mathrm{C}$ & $30.10 \pm 0.01$ & $564.20 \pm 0.01$ & $00.38 \pm 0.01$ \\
\hline
\end{tabular}

n: Number of samples, SD: Standard deviation, OTE: Optimized batch of transethosomes, PDI: Polydispersity index

comparatively more loss of drug occurred, and at $40^{\circ} \mathrm{C}$, loss was found to be highest. This may be explained on the basis of fact that due to loss of rigidity of vesicles at high temperature, they assemble to retain the drug. Increase in fluidity (loss of rigidity) at higher temperature is due to a phase transition. Vesicle size of the formulation also increased at high temperature $\left(25 \pm 3^{\circ} \mathrm{C}\right.$ and $\left.40 \pm 3^{\circ} \mathrm{C}\right)$ which may be due to increase in the rate of aggregation of vesicles which were found comparatively less at low temperature $\left(5 \pm 3^{\circ} \mathrm{C}\right)$. It was, therefore, concluded that formulation should be kept under refrigerated conditions $\left(5 \pm 3^{\circ} \mathrm{C}\right)$ to avoid any kind of stability problem [14].

\section{Characterization of vesicular topical gel}

The prepared gel was transparent having $\mathrm{pH} 7.4$ and viscosity 6145.6 cps. Data obtained from skin permeation studies (Fig. 2) revealed that at $24 \mathrm{~h}$, OTE gel (OTEG) showed the highest permeation of the drug (57.5\%) whereas, liposomes showed least permeation (16.9\%). Skin retention potential of vesicles was also calculated, and it was observed that OTEG showed highest skin retention potential (21.2\%) followed by TG, EG, and LG, i.e. 14.9\%, 10.3\%, and 9.5\%, respectively (Fig.3).

\section{Analysis of release mechanism}

Drug release data were explored for the type of mechanism involved. Release kinetics of OTEG, EG, TG, and LG were studied using different kinetic equations (zero-order, first-order, Hixson-Crowell model, and Higuchi model). The best fit with a highest correlation coefficient $\left(r^{2}\right)$ was chosen as the kinetic model. The results revealed that all the vesicle-based gel (i.e., OTE, EG, TG, and LG) showed highest correlation coefficient using Hixon-Crowell model. This indicated that the vesicular gel followed Hixson-Crowell which revealed that the gel formed an erodible matrix. Hence, it was concluded that the gel showed anomalous diffusion indicating that the formulation showed a controlled release pattern which would reduce the frequency of administration and increase patient compliance [15]

\section{CONCLUSION}

In this present study, TE was prepared containing PL 90 G, Span 80, and ethanol. These were evaluated for their drug permeation and retention at $24 \mathrm{~h}$, vesicle size, and entrapment efficiency. BBD was used to optimize the ratios of PL 90 G, Span 80, and ethanol. Formulation with a high percentage of ethanol (30\%) and lipid: Span ratio of 95:5 was found to show optimum characteristics. The developed TE based formulation was found to be more effective when compared to other vesicular delivery systems (i.e., L, E, and T) in terms of skin permeation of drug at $24 \mathrm{~h}$, skin retention, vesicle size, and entrapment efficiency. The prepared formulation was found stable at $5 \pm 3^{\circ} \mathrm{C}$ for 180 days. The OTE loaded with curcumin was incorporated into gel composed of $1 \% \mathrm{w} / \mathrm{w}$ Carbopol and evaluated for rheology, permeation of drug, and drug retention in the skin. The highest drug permeation, as well as drug retention in skin prolonged drug release, was observed with OTEG. The Hixson-Crowell model of release kinetics revealed that the gel released the drug as an erodible manner. Hence, it can be concluded that the developed TE was found superior over other vesicular delivery systems and have been successfully applied as a carrier to topical delivery in the form of a gel. However, the obtained results of in vitro and ex vivo experiments need to be correlated with in vivo studies. 


\section{REFERENCES}

1. Jurenka JS. Anti-inflammatory properties of curcumin, a major constituent of curcuma longa: A review of preclinical and clinical research. Altern Med Rev 2009;14:141-53.

2. Gupta SC, Patchva S, Aggarwal BB. Therapeutic roles of curcumin: Lessons learned from clinical trials. AAPS J 2013;15:195-218.

3. Sharma S, Pawar S, Jain UK. Development and evaluation of topical gel of curcumin from different combination of polymers formulation and evaluation of herbal gel. Int J Pharm Sci 2012;4:452-6.

4. Prakash PR, Rao NG, Soujanya C. Formulation, evaluation and antiinflammatory activity of topical etoricoxib gel. Asian J Pharm Clin Res 2010;3:126-9.

5. Garg V, Singh H, Bimbrawh S, Singh SK, Gulati M, Vaidya Y, et al. Ethosomes and transfersomes: Principles, perspectives and practices. Curr Drug Deliv 2017;14:613-33.

6. Garg V, Singh H, Bhatia A, Raza K, Singh SK, Singh B, et al. Systematic development of transethosomal gel system of piroxicam: Formulation optimization, in vitro evaluation, and ex vivo assessment. AAPS PharmSciTech 2017;18:58-71.

7. Ascenso A, Raposo S, Batista C, Cardoso P, Mendes T, Praça FG, et al. Development, characterization, and skin delivery studies of related ultradeformable vesicles: Transfersomes, ethosomes, and transethosomes. Int J Nanomedicine 2015;10:5837-51.
8. Patel KK, Kumar P, Thakkar HP. Formulation of niosomal gel for enhanced transdermal lopinavir delivery and its comparative evaluation with ethosomal gel. AAPS PharmSciTech 2012;13:1502-10.

9. Kamath MP, Shenoy BD, Tiwari SB, Karki R, Udupa N, Kotian M, et al. Prolonged release biodegradable vesicular carriers for rifampicin - formulation and kinetics of release. Indian J Exp Biol 2000;38:113-8

10. Grafmüller A, Shillcock J, Lipowsky R. The fusion of membranes and vesicles: Pathway and energy barriers from dissipative particle dynamics. Biophys J 2009;96:2658-75.

11. Singare DS, Marella S, Gowthamrajan K, Kulkarni GT, Vooturi R, Rao PS, et al. Optimization of formulation and process variable of nanosuspension: An industrial perspective. Int J Pharm 2010;402:213-20.

12. Sood S, Jain K, Gowthamarajan K. Optimization of curcumin nanoemulsion for intranasal delivery using design of experiment and its toxicity assessment. Colloids Surf B Biointerfaces 2014;113:330-7.

13. Pathan IB, Nandure H, Syed SM, Bairag S. Transdermal delivery of ethosomes as a novel vesicular carrier for paroxetine hydrochloride: In vitro evaluation and In vivo study. Marmara Pharm J 2016;20:1-6.

14. Raza K, Singh B, Mahajan A, Negi P, Bhatia A, Katare OP. Design and evaluation of flexible membrane vesicles (FMVs) for enhanced topical delivery of capsaicin. J Drug Target 2011;19:293-302.

15. Ruckmani K, Sankar V. Formulation and optimization of zidovudine niosomes. AAPS PharmSciTech 2010;11:1119-27. 